\title{
Organizational-technological decisions in construction based on neural network models
}

\author{
Iaroslav Zharov ${ }^{1, *}$ \\ ${ }^{1}$ Moscow State University of Civil Engineering, Yaroslavskoe shosse, 26, Moscow, 129337, Russia
}

\begin{abstract}
Increasing the quality of organizational and technological solutions in construction is one of the main tasks facing the construction industry. The actual methods of solving the problem of setting organizational and technological design are directly related to the integration of specialized software in the planning and design of construction projects, especially for unique, complex projects, projects implemented in tight time and construction sites in the current urban development. The existing need to process a significant amount of information at short intervals and to link design decisions to the dynamic environment of the construction site is not an easy task, but a realizable one. Within the framework of the research work carried out at the department of MGSU, the expediency of applying operational assessments of the parameters of organizational and technological solutions based on mathematical methods has been established. The proposed method for forecasting and evaluating the integral parameters of design solutions is based on a neural network model, the method used involves the formation of a training matrix comprising key indicators of implemented (pilot) ones.
\end{abstract}

\section{Introduction}

Methods of computer modeling are developing along the path of building a coordinate system and now 3D models are being transformed into 6D models, which include, in addition to spatial coordinates, time, cost, and technological [1]. Project organizations in their work rely on geological information systems, apply a wide range of ERP-systems, PM-programs, in special cases, specialized software complexes for the implementation of design and technological calculations [2]. In general, the effectiveness of the concept of information modeling has been proved both in scientific circles and on real projects, but the creation of such models is still extremely time-consuming and expedient only when used throughout the life cycle of the project [3]. Despite the seemingly high efficiency of the work of design organizations, compliance with the schedule of work by the contractor organization remains an extremely difficult task, and for frequent and unachievable for objective reasons and the impacts of anthropogenic and social nature that arise during the implementation of the project. In this case, it is advisable to concentrate on aspects that can be modeled with modern information systems, one of which is the weak linkage of organizational and technological solutions in parallel and in-line methods of work [4].

\footnotetext{
*Corresponding author: zharovyav@mgsu.ru
} 


\section{Methods}

Within the framework of the system approach to solving problems of organizational and technological modeling, when choosing the optimal variant of a design and technological solution, it is necessary to focus on such criteria: the estimated cost of the project, the terms of implementation, the quality parameters of the facility. It is necessary to take into account the list of risks that accompany the implementation of technological solution options (technology, spatial position relative to surrounding objects, structural components) [10]. When choosing an organizational and technological solution, it is necessary to use models that allow to take into account the synergistic effect of the factors on which the implementation of the project depends. Within the framework of this article, it is proposed to use the empirical method to construct models and their application for evaluating organizational and technological solutions at the stage of organizational and technological design.

To determine the role and place of the tool for rapid assessment of the parameters of organizational and technological solutions in the project implementation structure, we will consider it in detail. In the most general form, the procedure for implementing an investment and construction project can be broken down into stages (see Figure 1). Errors in the development of project organizational and technological solutions still in the early stages of the project, may eventually lead to a significant deviation of the time, cost and technical parameters of the project. Taking into account the resource intensity of design and survey works, the coordination of design and organizational and technological solutions and the need to approve the final version of the project, along with the deep integration of these processes into the schedule of the investment and construction project, errors and shortcomings in the project at these stages are the most critical for the main performance indicators project [11-13].

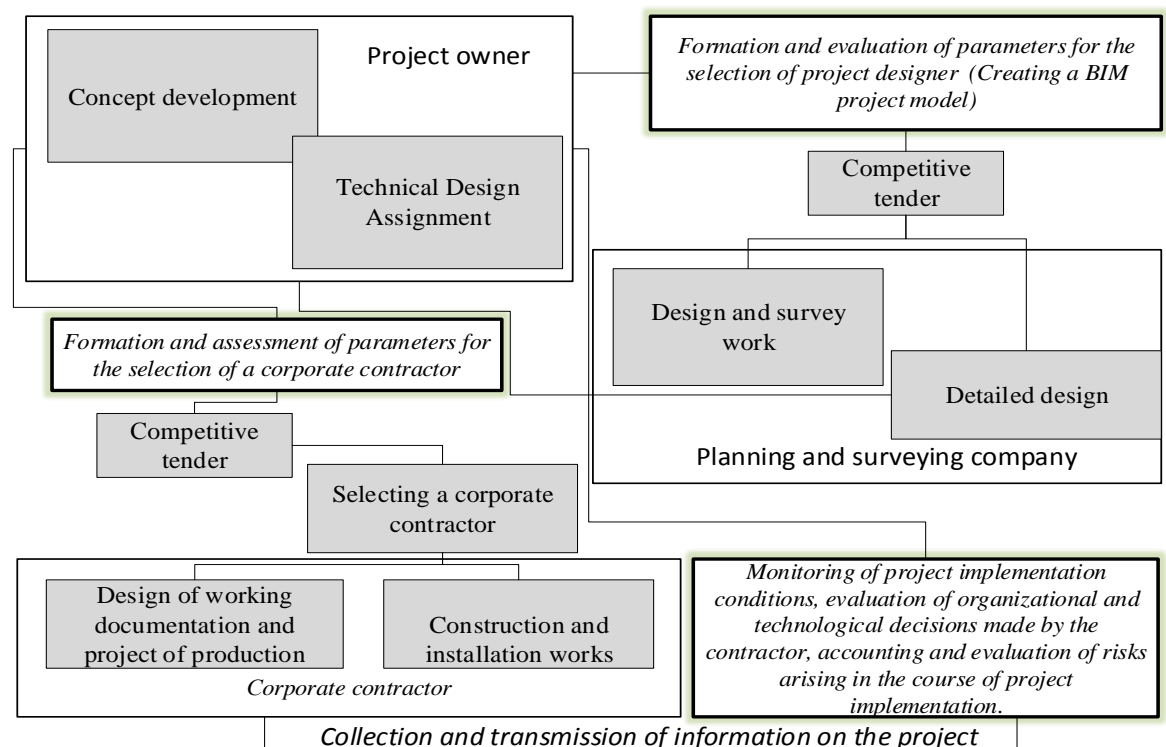

Fig.1. Stages of implementation of the investment and construction project.

In order to improve the quality of design solutions, it is advisable to apply current design methods based on information modeling technology, with the creation of a comprehensive model for the implementation of both the construction and the operational part of the 
investment and construction project. Along with the creation of better project documentation, a considerable amount of time is generated to reduce the resource costs for creating working documentation, similar methods allow detailed consideration of the choice of the contractor $[14,15]$.

Assessment of the parameters of organizational and technological solutions. The formation of an organizational and technological solution is a resource-intensive process, with a large number of involved participants and stakeholders. That is why, and because of the inability to find optimal solutions based on strict mathematical criteria and formal methods, when evaluating construction projects it is necessary to use expert information. The main priorities that are taken into account in the implementation of any investment and construction project include: reducing the cost of construction ( $K c \rightarrow$ min ), reducing construction time, ( $K t \rightarrow$ min ), ensuring production, environmental safety during the implementation of the project ( $K \delta \rightarrow \min$ ) and ensuring operational reliability ( $K \ni \rightarrow \max$ ) [16].

\section{Results and Discussion}

The starting point for the initiation of the process of designing an organizational and technological solution is the functional purpose and design and technological parameters of the facility. The duration of the implementation of individual processes can be increased and combined with other processes to optimize the cost of work [17,18]. Based on this information, the design organization or engineering company prepares options for organizational and technological solutions $D_{1}, D_{2}, \ldots, D_{n}$, taking into account:

- design features of the facility;

- External restrictions of the construction site (spatial restrictions, temporary, transport accessibility, etc.);

- availability of labor resources in the construction area;

- the possibility of using certain machines and mechanisms (lifting mechanisms, tunnel drilling rigs, mechanisms and devices for constructing linear objects)

Based on the tasks of organizational and technological design, the organizational and technological process can be represented in the form of an information model ( $O_{i}$ - parameters characterizing the external environment of the object; $T_{i}$ - parameters of the organizational and technological solution; $I_{c i}, I_{t i}$ - integral characteristics of the project: project cost, terms of its implementation; $C_{i}$ - constructive parameters of the object):

$$
D_{i}\left\{O_{i}, T_{i}, I_{c i}, I_{t i}, C_{i}\right\}
$$

To assess the options for organizational and technological solutions, at the stage of their adoption it is necessary to take into account alongside with the integral characteristics of the information model $\left(I_{c i}, I_{t i}\right)$ the likelihood of the reliability of the implementation of the design solution without significant deviations from the design quality parameters. The use of certain technologies and individual design parameters of building products in different environmental conditions has various risks. The model of effective accounting for such risks is based on the tool for rapid assessment of the parameters of organizational and technological solutions.

If we consider $n$ options for an organizational and technological solution $D_{1}, D_{2}, \ldots, D_{n}$, then for each of which are defined $\left\{I_{c 1}, I_{t 1}\right\}=y_{1}, \ldots .,\left\{I_{c n}, I_{t n}\right\}=y_{n}$. In 
this case, the actual values will differ from the design values $y_{1 \phi}, y_{2 \phi}, \ldots, y_{n \phi}$.

$$
\delta_{i}=y_{i \phi}-y_{\text {in }}, i=[l, n]
$$

Based on key indicators or in the case of the availability of detailed design and technological and budget documentation on previously implemented construction projects. Form the training matrix $-M L$. The training matrix provides a link between the terms of the project implementation, the organizational and technological solution, and the integral parameters of the project.

The composition of the training matrix includes the following elements $\left(O_{j 1 \ldots n}\right.$ - parameters characterizing the external environment of the object; $T_{i k}$ - parameters of organizational and technological solutions, given by the operator, for the assessment of this technology; $p$ - the number of options considered for organizational and technological solutions of a single task; $\delta_{j}$ - deviation of the planned indicators for the project from the actual values for the integral parameters of the project):

$$
O_{j 1}, O_{j 2}, \ldots, O_{j n}, T_{i 1 k}, T_{i 2 k}, \ldots, T_{i p k}, \delta_{j}
$$

If training examples that fill the matrix can be quite heterogeneous, the specific method of coding during the processing process depends on the model that we want to use for evaluation. In general, this model looks like:

$$
\delta=f(D)\left\{O_{i}, T_{i}, I_{c i}, I_{t i}, C_{i}\right\}
$$

\section{Conclusions}

The optimal way to solve the constructed model, taking into account the amount of available information for the formation of learning examples, may be models of the neural network of the reverse distribution, it is possible to combine the neural network approach with the apparatus of fuzzy sets.

In general, the decision-making procedure includes the following stages:

- Creation of training matrices - including data on previously implemented objects;

- building a model based on learning matrices;

- calculation of predicted risk indicators for all potentially feasible organizational and technological solutions.

Imposition of assumptions and limitations: in the calculation, we assume that the external conditions are unchanged for the variants.

As a result of applying the described method of rapid assessment of the parameters of organizational and technological solutions, their choice for a particular construction object becomes more justified, by taking into account the total risks.

In cases of application of this approach for the development and adoption of organizational and technological solutions for the design and construction of unique and complex facilities, it should be noted that obtaining the accuracy of results is achieved by considering the totality of individual organizational and technological solutions for the project.

\section{References}

1. S. Sborshikov. Organizational methods of activization of scientific and technical and innovation activities in construction on the basis of territorial and industrial technology parks [Text]: the thesis of Cand.Tech.Sci. 08.00.28 (2000) 
2. Ia. Zharov. Solving the problems of organizational and technological design using multidimensional modelling methods. // Systems. Methods. Technologies. № 3 (31). (2016)

3. S. Sborshikov. Logistics of Regulatory Impacts in the Investment and Construction Sphere (Theory, Methodology, Practice) [Text]: the thesis of Doc.Econom.Sci. 08.00 .05 (2012)

4. Papelniuk O. Systematization of Costs and Effects as a Method of Costs Management in Innovative Projects of Underground Construction // Procedia Engineering. T. 165. (2016)

5. S. Sborshikov., N. Lazareva, Ya. Zharov. The basic theoretical provisions of logistics of regulatory influences in the investment and construction sphere // Vestnik MGSU. № 7. (2014)

6. S. Sborshikov, N. Lazareva, Ia. Zharov. Vestnik MGSU. 2, 210 (2014)

7. A. Aleksanin, S. Sborshikov. MATEC Web of Conferences. 86, 05013 (2016)

8. P. Zhuravlev. Vestnik ISTU. 9, 174 (2015)

9. Aleksanin A., Sborshikov S. Specifics of system of external influences on the life cycle of a construction object // Matec web of conferences 5.

10. "5th international scientific conference" Integration, Partnership and Innovation in Construction Science and Education. IPICSE 2016. (2016)

11. A. Aleksanin. Vestnik MGSU. 1, 164 (2009)

12. Ia. Zharov. Industrial and Civil Engineering. 5, 69 (2013)

13. N. Zhang S. et al. Building information modeling (BIM) and safety: Automatic safety checking of construction models and schedules //Automation in Construction. T. 29 (2013)

14. Shou W. et al. A comparative review of building information modelling implementation in building and infrastructure industries //Archives of computational methods in engineering. T. 22. №. 2. (2015)

15. Chong H. Y., Wang X. The outlook of building information modeling for sustainable development // Clean Technologies and Environmental Policy. T. 18. №. 6. (2016)

16. Porras-Díaz H. et al. Technologies" Building Information Modeling" budgeting in construction of reinforced structures // Entramado. T. 11. №. 1. (2015)

17. K. Jones, B. Martin, P. Winslow. The Structural Engineer. 95, 14 (2017)

18. N. Shumeyko. Estimated contract work in construction. 1, 19 (2016)

19. E. Bahus. Scientific review. 14, 20 (2016)

20. Kim C.Y., Hong S.W. Fuzzy logic approach for the design of reinforcement in tunnel excavation. Korea. Geotechnical Engineering Reserch. Dept. (2004)

21. Tah J.H.M. and Carr.V. A proposal for construction project risk assessment using fuzzy logic // Construction Management and Economics. (2000) 